\title{
Exploration of the Biochemical Assessment of Patients Infected with COVID-19 Hospitalized in Two Health Structures in Bamako, Mali
}

\author{
Mamadou Diarra*, Issa Cissé, Moumine Diamouténé \\ Biochemistry Laboratory of the National Institute of Public Health BP: E1771-Bamako, Mali \\ *Corresponding Author: Mamadou Diarra, Biochemistry Laboratory of the National Institute of Public \\ Health BP: E1771-Bamako, Mali
}

\begin{abstract}
:
Introduction:

The SARS-CoV-2 virus is responsible for a disease called COVID-19. Some publications have been the subject of parameter panels that can best inform medical teams about the condition of their patients. All patients benefit from a biochemical assessment upon admission and then during hospitalization. The objective of this study is to identify the characteristics of certain biochemical parameters in patients infected with COVID-19 in Mali.
\end{abstract}

Material and Methods:

The blood samples taken from these hospitalized patients were analyzed in the Biochemistry laboratory of the National Institute of Public Health (INSP). Data were entered and analyzed in Excel and SPSS.

Results and Discussion:

Our sample is made up of $54.10 \%$ women versus $45.90 \%$ of men aged 3 to 93. The blood levels are: glucose $6.45 \pm 2.85 \mathrm{mmol} / \mathrm{L}$, creatinine $132.58 \pm 115 \mu \mathrm{mol} / \mathrm{L}$ for men and $102.32 \pm 110 \mu \mathrm{mol} / \mathrm{L}$ for women, AST $39.16 \pm 32 \mathrm{IU} / \mathrm{L}$, ALAT $31.95 \pm 25 \mathrm{IU} / \mathrm{L}$ and CRP $12.40 \pm 17 \mathrm{mg} / \mathrm{L}$. We have seen an increase in all of these parameters.

Conclusion:

Poor control of these parameters can lead to a complication of the disease, especially in people at risk.

Keywords: Assessment, biochemical, COVID-19, Mali

Abbreviations: SARS-CoV-2: Severe Acute Respiratory Syndrome - Corona virus-2, COVID-19: Corona Virus - Disease 2019, INSP: the National Institute of Public Health, SPSS: Statistical Package for the Social Sciences, IFCC: the International federation of clinical chemistry, ASAT: Aspartate Amino-Transferase, ALAT: Alanine Amino-Transferase, CRP: Reactive C-Proteins

\section{INTRODUCTION}

The SARS-CoV-2 virus is responsible for an epidemic disease called COVID-19, initially identified in Wuhan (China) and which spread very quickly in China and then throughout the world. According to WHO, a patient who meets the following clinical criteria would have COVID-19: sudden onset of fever and cough or sudden onset of at least three of certain signs or symptoms (fever, cough, general weakness / fatigue, changes in mental state) [1].

As of March, publications relating to the biological assessment of affected patients were the subject of a proposal for panels of parameters that could best inform medical teams about the condition of their patients $[2,3]$. Some of this work led to the publication of a list of parameters recommended by the International Federation of Clinical Chemistry (IFCC) in mid-April [4].

Large uncertainties remain regarding the pathophysiology of SARS-Cov-2 infection. The medical and biological care, required to adapt within short deadlines, are not all the subject of a known consensus 
and / or widely disseminated, or even applied [5]. All patients benefit from laboratory tests including certain biochemical parameters upon admission and then during hospitalization.

In Mali, the first case was confirmed on March 26, 2020 in Bamako. Therefore, serious cases hospitalized in certain health structures (Point G Hospital, Dermatological Hospital, Mali Hospital, etc.) are subject to biological monitoring. The objective of this study is to identify the characteristics of certain biochemical parameters in patients infected with COVID-19.

\section{MATERIAL AND METHODS}

The data were collected during the first quarter of 2021, from January 1 to March 31 as part of the biological monitoring of patients infected with COVID-19 and hospitalized in two public hospitals in Bamako: Dermatological Hospital and Point G Hospital. of blood were carried out on dry tubes in patients hospitalized in these two hospitals and immediately sent to the Biochemistry laboratory of the National Institute of Public Health (INSP). These blood samples were analyzed on the "KENZA 240 ISE" biochemical machine with "BioLabo" brand reagents for the determination of the level of biochemical parameters. Data were entered and analyzed in Excel and SPSS.

\section{RESULTS AND DISCUSSION}

\subsection{Distribution of the Sample by Sex and Age Groups}

Our sample is mainly composed of $54.10 \%$ women against $45.90 \%$ of men. This could be explained by the composition of the Malian population where there are more women than men according to the results of the demographic survey.

The average age is 45.96 years old and the median is 45 years old. The youngest is 3 years old and the oldest is 93 years old. The distribution of the sample by age groups is summarized in Figure $\mathrm{N}^{\circ} 1$

The age group most affected is that of "Over 60 years" with $27.50 \%$ and the least affected is that " 0 10 years" with $2.80 \%$. These results confirm those published by M. Maamar et al in 2020 according to which the risk of hospitalization for COVID-19 is higher in the "Over 64" age group [6].

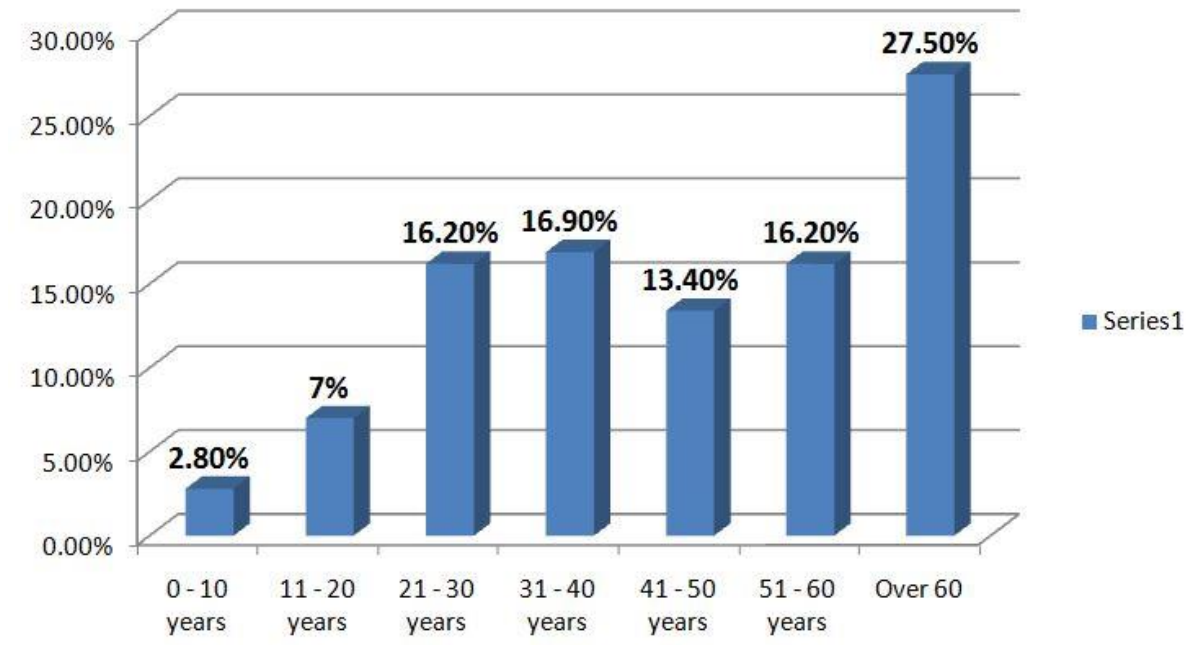

Figure1. Distribution of the sample by age groups

\subsection{Distribution of the Sample by Blood Glucose Level}

The level of glucose in the blood is $6.45 \pm 2.85 \mathrm{mmol} / \mathrm{L}$. The distribution of glucose levels in the blood according to the reference values is shown in figure $\mathrm{N}^{\circ} 2$

Among patients hospitalized for COVID-19 on admission, $38.50 \%$ or more than $1 / 3$ have hyperglycemia compared with $6.10 \%$ hypoglycemia and $55.40 \%$ have normal blood sugar. High blood sugar and especially diabetes are risk factors for COVID-19.

These results are similar to those published by Wu C and Chen N in 2020 [7,8]. 


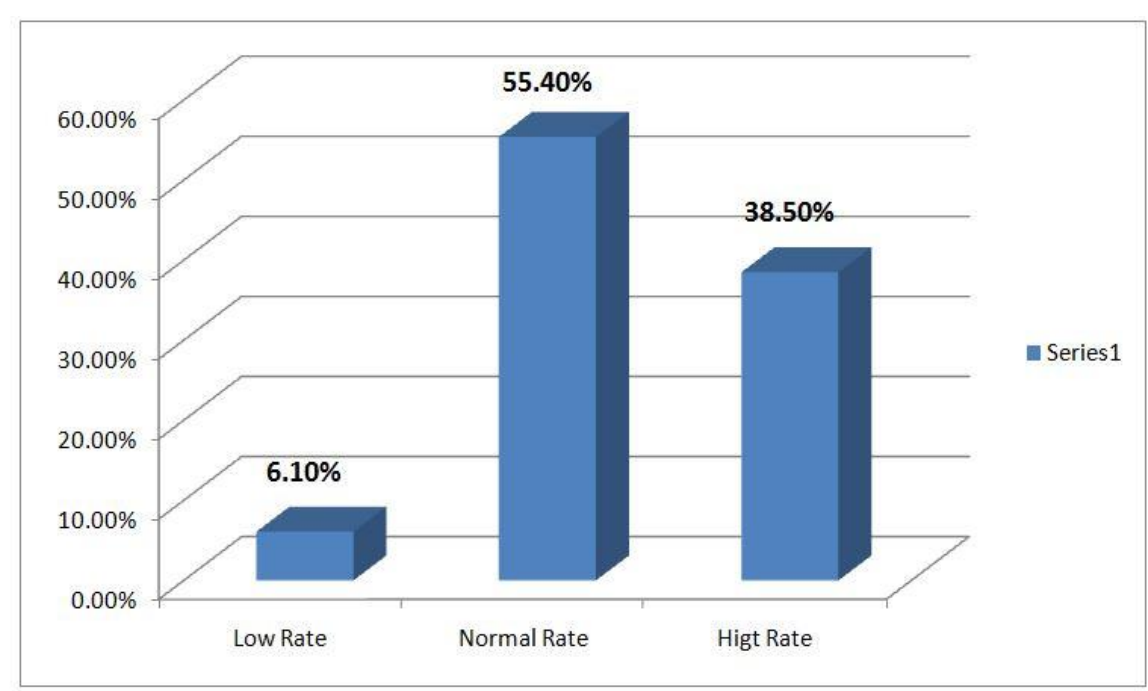

Figure2. Distribution of the sample by blood glucose level

\subsection{Distribution of the Sample by Creatinine Level in the Blood}

The average creatinine level in the blood is $132.58 \pm 115 \mu \mathrm{mol} / \mathrm{L}$ for males against $102.32 \pm 110$ $\mu \mathrm{mol} / \mathrm{L}$ for females. The distribution of the creatinine levels in the blood according to the reference values is shown in figure No. 3 .

$65 \%$ of hospitalized patients have normal blood creatinine levels and $27.28 \%$ have high levels versus $7.72 \%$ low levels. Almost 1/3 of patients have an elevated blood creatinine level and the averages for both sexes are above those of the upper limits of the reference values. These results are in the same direction as those observed by Placais L et al. Louhaichi S et al. then Guan WJ et al. in 2020 when there was an increase in blood creatinine levels in patients infected with COVID-19 [9,10,11].

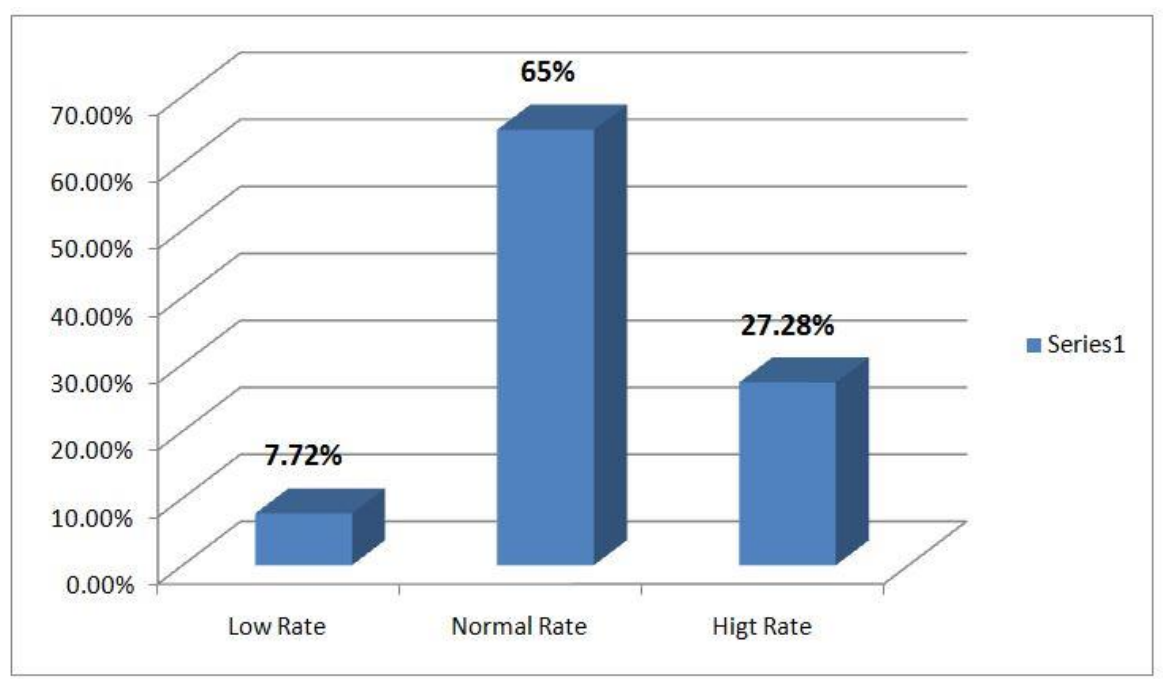

Figure3. Distribution of the sample by creatinine level in the blood

\subsection{Distribution of the Sample by Level of Transaminases in the Blood}

The average level of Aspartate Amino-Transferase (ASAT) in the blood of patients hospitalized with COVID-19 is $39.16 \pm 32 \mathrm{IU} / \mathrm{L}$. The average level of Alanine Amino-Transferase (ALAT) in the blood of patients hospitalized for COVID-19 is $31.95 \pm 25 \mathrm{IU} / \mathrm{L}$. The distribution of the levels of transaminases in the blood according to the reference values is represented in figure $\mathrm{N}^{\circ} 4$.

$25.20 \%$ of patients have an elevated blood ASAT level compared to $74.80 \%$ of the normal level. $18.70 \%$ of the sample have an elevated blood ALT level compared to $81.30 \%$ of normal level. These results are contrary to those obtained by Placais L et al in 2020 where there was an increase in blood transaminase levels in patients infected with COVID-19 [9]. 


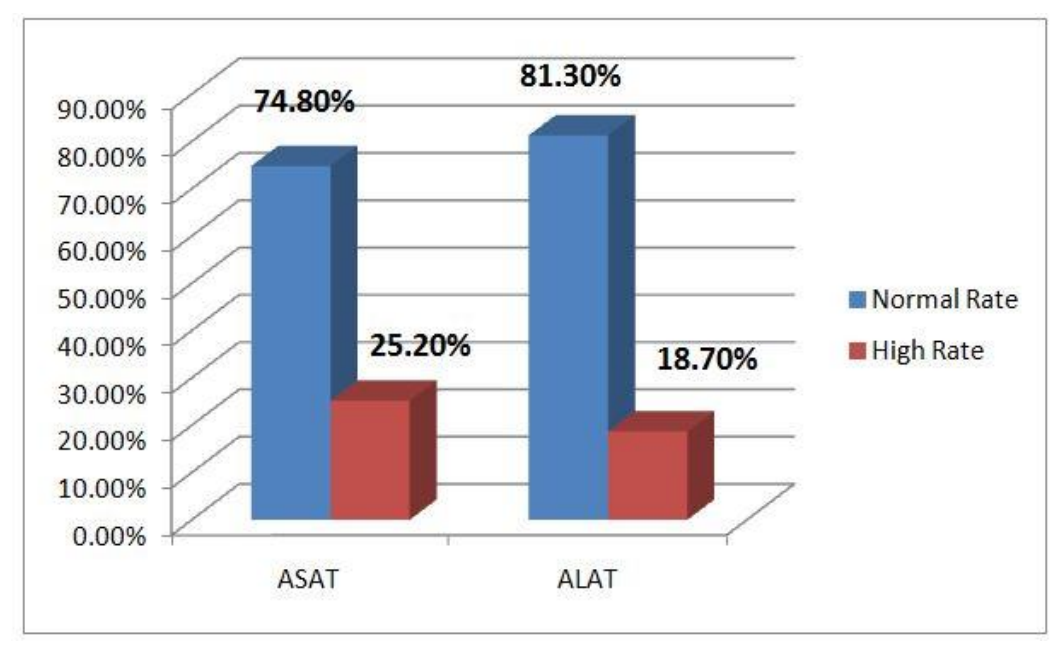

Figure4. Distribution of the sample by level of transaminase in the blood

\subsection{Distribution of the Sample by Level of C-Reactive Proteins (CRP) in the Blood}

The average level of reactive protein-C (CRP) in the blood of patients hospitalized with COVID-19 is $12.40 \pm 17 \mathrm{mg} / \mathrm{L}$. The distribution of the CRP levels in the blood according to the reference values is shown in Figure 5.

$31.10 \%$ of patients have a high CRP level compared to $68.90 \%$ of normal rate. In general, CRP levels are relatively high. These results are in the same direction as those observed by Placais L et al. then by Louhaichi S et al. in 2020 when there was an increase in blood CRP levels in patients infected with COVID-19 $[9,10]$.

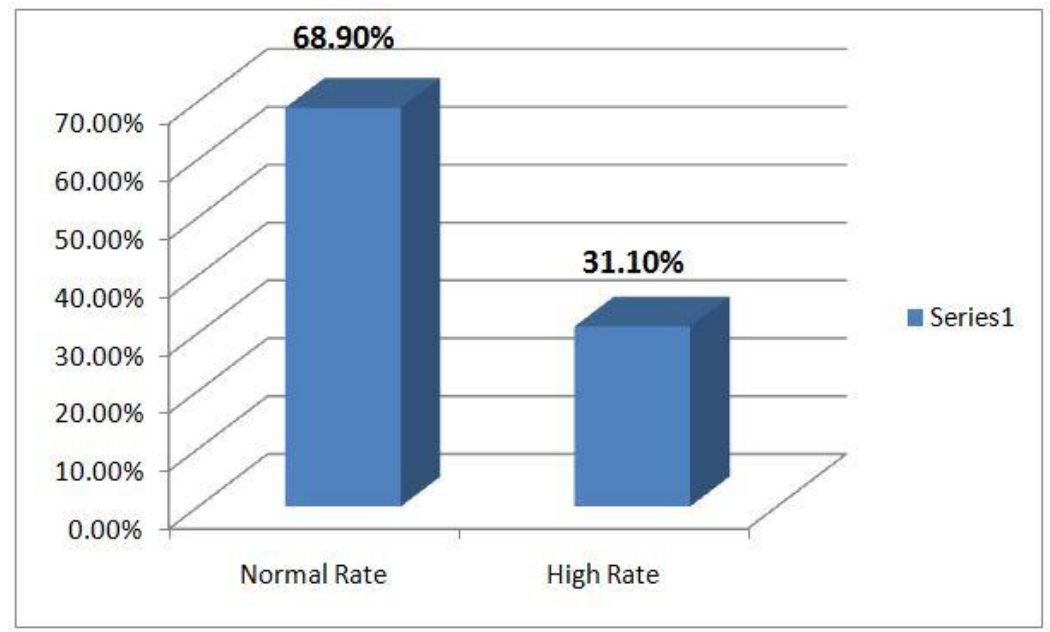

Figure5. Distribution of the sample by level of CRP in the blood

\section{CONCLuSiON}

Sars-CoV-2 can affect all ages. The risk of hospitalization is higher in the elderly and those living with chronic illness. All biochemical parameters observed in this study are affected. Poor control of these parameters can lead to a complication of the disease, especially in people at risk.

\section{REFERENCES}

[1] OMS, Définitions de cas de COVID-19, 2020

[2] Lippi G, Plebani M. The critical role of laboratory medicine during coronavirus disease 2019 (COVID-19) and other viral outbreaks. Clin Chem Lab Med. 2020. [doi: 10.1515/cclm-2020-0240].

[3] Aggarwal S, Garcia-Telles N, Aggarwal G, Lavie C, Lippi G, Henry BM. Clinical features, laboratory characteristics, and outcomes of patients hospitalized with coronavirus disease 2019 (COVID-19): Early report from the United States. Diagnosis (Berl). 2020. [doi: 10.1515/dx-2020-0046].

[4] https://www.ifcc.org/ifcc-news/2020-03-26-ifcc-information-guide-on-covid-19/. 
[5] MC Beauvieux, AM Bérard, I Aimone-Gastin. et al, Groupe de travail SFBC « Marqueurs biochimiques de COVID-19, Annales de Biologie Volume 78, numéro 3, 2020, P 270

[6] M. Maamar*, H. Khibri, H. Harmouche, W. Ammouri,Z. Tazi-Mezalek, M. Adnaoui, Impact du confinement sur la santé des personnes âgées durant la pandémie COVID-19, NPG Neurologie Psychiatrie - Gériatrie, Volume 20, Issue 120, Décembre 2020, Pages 322-325

[7] Wu C, Chen X, Cai Y, Xia J, Zhou X, Xu S, et al. Risk factors associated with acute respiratory distress syndrome and death in patients with Coronavirus disease 2019 pneumonia in Wuhan, China. JAMA Intern Med. 2020 Mar 13;:e200994. Epub 2020/03/14. [PMC free article] [PubMed] [Google Scholar]

[8] Chen N, Zhou M, Dong X, Qu J, Gong F, Han Y, et al. Epidemiological and clinical characteristics of 99 cases of 2019 novel coronavirus pneumonia in Wuhan, China: a descriptive study. Lancet. 2020;395 (10223):507-13. [PMC free article] [PubMed] [Google Scholar]

[9] Placais L, Richier Q. COVID-19: clinical, biological and radiological characteristics in adults, infants and pregnant women. An up-to-date review at the heart of the pandemic. Rev Med Interne. 2020;41(5):308-18. [PMC free article] [PubMed] [Google Scholar]

[10] Louhaichi S, Allouche A, Baili H, Jrad S, Radhouani A, Greb D, et al. Features of patients with 2019 novel coronavirus admitted in a pneumology department: The first retrospective Tunisian case series. Tunis Med. 2020;98(4):261-5. [PubMed] [Google Scholar]

[11] Guan WJ, Ni ZY, Hu Y, Liang WH, Ou CQ, He JX, et al. Clinical characteristics of Coronavirus disease 2019 in China. N Engl J Med. 2020;382 (18):1708-20. [PMC free article] [PubMed] [Google Scholar]

Citation: Mamadou Diarra et al." Exploration of the Biochemical Assessment of Patients Infected with COVID-19 Hospitalized in Two Health Structures in Bamako, Mali", International Journal of Clinical Chemistry and Laboratory Medicine (IJCCLM), vol. 7, no.1, pp. 41-45, 2021. http://dx.doi.org/10.20431/ 2455-7153.0701005

Copyright: (C) 2021 Authors. This is an open-access article distributed under the terms of the Creative Commons Attribution License, which permits unrestricted use, distribution, and reproduction in any medium, provided the original author and source are credited. 